\title{
Are parenchymal AVMs congenital lesions?
}

\author{
Saul F. Morales-Valero, M.D., ${ }^{1}$ Carlo Bortolotti, M.D., ${ }^{2}$ Carmelo Sturiale, M.D., ${ }^{2}$ \\ AND GiusePPe LanZino, M.D. ${ }^{1}$ \\ ${ }^{1}$ Department of Neurologic Surgery, Mayo Clinic, Mayo Medical School, Rochester, Minnesota; and \\ ${ }^{2}$ Department of Neurosurgery, IRCCS Institute of Neurological Sciences, Bellaria Hospital, Bologna, Italy
}

\begin{abstract}
A long-held dogma in neurosurgery is that parenchymal arteriovenous malformations (AVMs) are congenital. However, there is no strong evidence supporting this theory. An increasing number of documented cases of de novo formation of parenchymal AVMs cast doubt on their congenital nature and suggest that indeed the majority of these lesions may form after birth. Further evidence suggesting the postnatal development of parenchymal AVMs comes from the exceedingly rare diagnosis of these lesions in utero despite the widespread availability of high-resolution imaging modalities such as ultrasound and fetal MRI. The exact mechanism of AVM formation has yet to be elucidated, but most likely involves genetic susceptibility and environmental triggering factors. In this review, the authors report 2 cases of de novo AVM formation and analyze the evidence suggesting that they represent an acquired condition.

(http://thejns.org/doi/abs/10.3171/2014.6.FOCUS14234)
\end{abstract}

\section{KEY WoRDS - cerebral arteriovenous malformations • de novo development • central nervous system vascular malformations $\quad$ - cerebrovascular disorders}

A LONG-HELD dogma in neurosurgery is that parenchymal arteriovenous malformations (AVMs) are congenital lesions. This dogma is based on the observation that these lesions can occur in children and adults alike, but there is little convincing evidence as to its scientific truth. Over the past 2 decades, our understanding of parenchymal AVMs has improved and more information has been gained about their molecular and genetic basis. An increasing number of convincing observations of de novo AVM formation have put into question the long-held dogma that these lesions are congenital. In this review, we describe 2 cases of de novo AVMs and analyze the evidence suggesting that indeed parenchymal AVMs are not congenital lesions but most likely represent an acquired condition probably not dissimilar to their dural counterparts.

\section{Case Reports}

Case 1

A 35-year-old woman with a history of liver cirrho-

Abbreviations used in this paper: AVM = arteriovenous malformation; $\mathrm{CNV}=$ copy number variation; $\mathrm{HHT}=$ hereditary hemorrhagic telangiectasia; ICA = internal carotid artery; SNP = singlenucleotide polymorphism. sis suffered a parenchymal bleed from a large parietooccipital AVM. High-resolution MRI done 4 years earlier, in the course of evaluation of confusion due to hepatic encephalopathy, had not shown any abnormal vascularity in the left parietooccipital area (Fig. 1).

\section{Case 2}

A 56-year-old man presenting with a transient neurological event underwent cerebral angiography. A left internal carotid artery (ICA) injection demonstrated an AVM with feeding vessels from the middle cerebral artery. An angiogram acquired 14 years earlier for evaluation of a transient ischemic attack did not show vascular malformations (Fig. 2).

\section{Discussion}

\section{Current Paradigm}

Based on observations of the normal development of the cerebral vasculature, it has been hypothesized that AVMs originate early during embryonic development in the interval when the embryo is between 40 and $80 \mathrm{~mm}$ in length. ${ }^{27}$ During this period, numerous processes such as vasculogenesis, angiogenesis, vascular remodeling, and differentiation take place, leading to a mature intracranial 

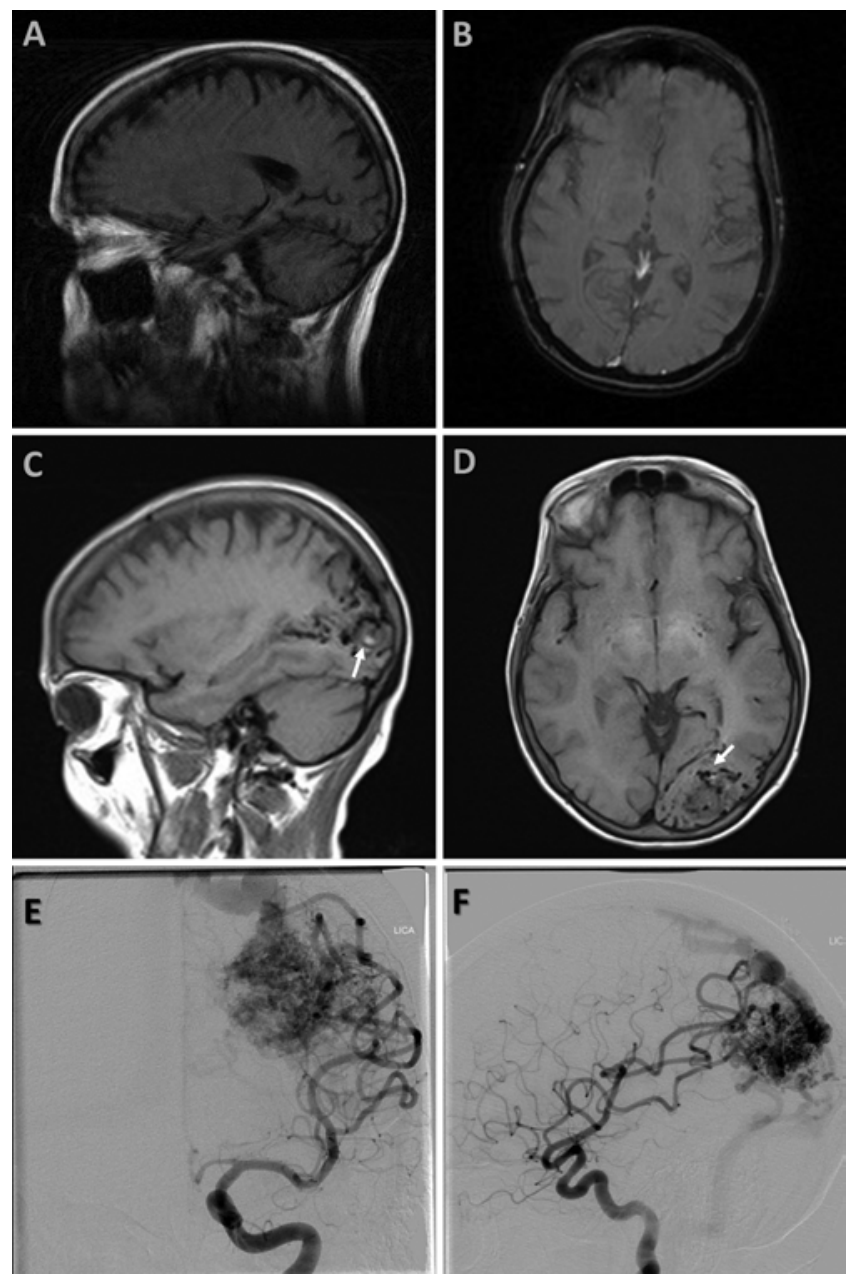

FIG. 1. Case 1. Baseline and repeat imaging. Initial imaging, performed in the setting of the patient's confusion due to hepatic encephalopathy, did not show any vascular abnormalities (sagittal T1-weighted FLAIR $[A]$ and axial gradient echo $[B]$ images). Four years later, she presented with sudden headache, and repeat MRI showed an AVM in the left parietooccipital area with a small area of T1 hyperintensity (arrows), suggesting an AVM with a small area of hemorrhage (sagittal T1weighted [C] and axial T1-weighted [D] images). Catheter angiography confirmed a large parietooccipital AVM (left ICA injection, anteroposterior $[E]$ and lateral $[F]$ views).

vasculature when the fetus reaches $80 \mathrm{~mm}$ in length. ${ }^{9,27}$ Based on this theory and on the observation that AVMs can be found in infants, it is commonly accepted that parenchymal AVMs are present at birth and follow a silent course before becoming clinically evident. ${ }^{3,32}$ This longheld theory is widely accepted even though there is little evidence that parenchymal AVMs are indeed congenital lesions.

\section{Clinical Evidence of De Novo Formation of AVMs}

A growing number of cases of de novo AVM formation are being documented, which challenges the concept of this lesion's congenital nature. Including the patients described in the present report, we were able to find 16 cases of de novo AVMs (Table 1). All of these patients had undergone high-resolution baseline imaging that showed no evidence of vascular malformations, although only 6 of these patients were initially evaluated with catheter angiography. The indications for the initial evaluation were variable. These included vascular abnormalities (such as moyamoya disease,,$^{15,28,31}$ dural arteriovenous fistula,,$^{14}$ cavernous malformation with developmental venous anomaly, ${ }^{4} \mathrm{AVMs}^{2}$ in other location, and intraparenchymal hemorrhage ${ }^{25}$ ) and nonvascular conditions such as a brain tumor, ${ }^{24}$ neuronal migration abnormality, ${ }^{33}$ Bell's palsy, ${ }^{23}$ head trauma,${ }^{16}$ and demyelinating lesions. ${ }^{7}$ Repeat imaging leading to the diagnosis of the de novo AVM was performed after a prolonged interval, ranging from 2 to 17 years, for the purpose of following up the original lesion or due to the acute development of symptoms (which were related to AVM rupture in 3 cases). The age distribution of these patients is wide, ranging from 6 to 68 years at the time of de novo AVM diagnosis (mean 26.4 years).

\section{Diagnosis of Intracranial Vascular Malformations in the Perinatal Period}

The refinement of prenatal imaging techniques such as 3D ultrasonography and fetal MRI has improved the rate of detection of anomalies such as neural tube defects and neuronal migration and proliferation disorders. ${ }^{29}$ Similarly, modern color Doppler ultrasound allows a thorough evaluation of the fetal cerebrovascular circulation. ${ }^{11}$ However, prenatal diagnosis of a parenchymal AVM is exceedingly rare, $, 50,13$ which is in contrast to other vascular lesions (for example, vein of Galen aneurysmal malformations) that are frequently detected in utero or shortly after birth. ${ }^{26}$ Furthermore, the number of AVMs diagnosed in the neonatal period is also limited, ${ }^{30}$ and it is estimated that only $1 \%$ of AVMs are diagnosed during the first 2 years of life. These facts further bring into question the assumption that AVMs develop early during embryonic development and are present at birth.

\section{Putative Mechanisms of AVM Formation}

The congenital nature of brain AVMs has been previously questioned by others, ${ }^{20,21,27}$ and as we have discussed, there is compelling evidence suggesting the postnatal development of many of these lesions. However, the exact mechanism of AVM formation has yet to be elucidated, and it may involve an interaction between genetic susceptibility and environmental (acquired) factors. Several studies of patients with hereditary hemorrhagic telangiectasia (HHT), an autosomal dominant disease that includes AVMs in multiple sites (brain included) as part of its clinical spectrum, ${ }^{18}$ have improved our understanding of these vascular lesions. Loss-of-function mutations have been identified in the 2 main subtypes of the disease. Specifically, the gene coding for endoglin (ENG) is altered in patients with HHT Type 1 and the gene coding for activin-like kinase 1 (ALK1) is mutated in patients with HHT Type 2. Both ENG and ALK1 are proteins involved in signaling pathways of the transforming growth factor- $\beta$, critical for angiogenesis and inflammation. ${ }^{18}$

A possible genetic influence in the formation of AVMs outside the setting of HHT is suggested by various reports of familial clustering of sporadic AVMs. ${ }^{35} \mathrm{In}$ addition, a variety of candidate gene studies in patients 

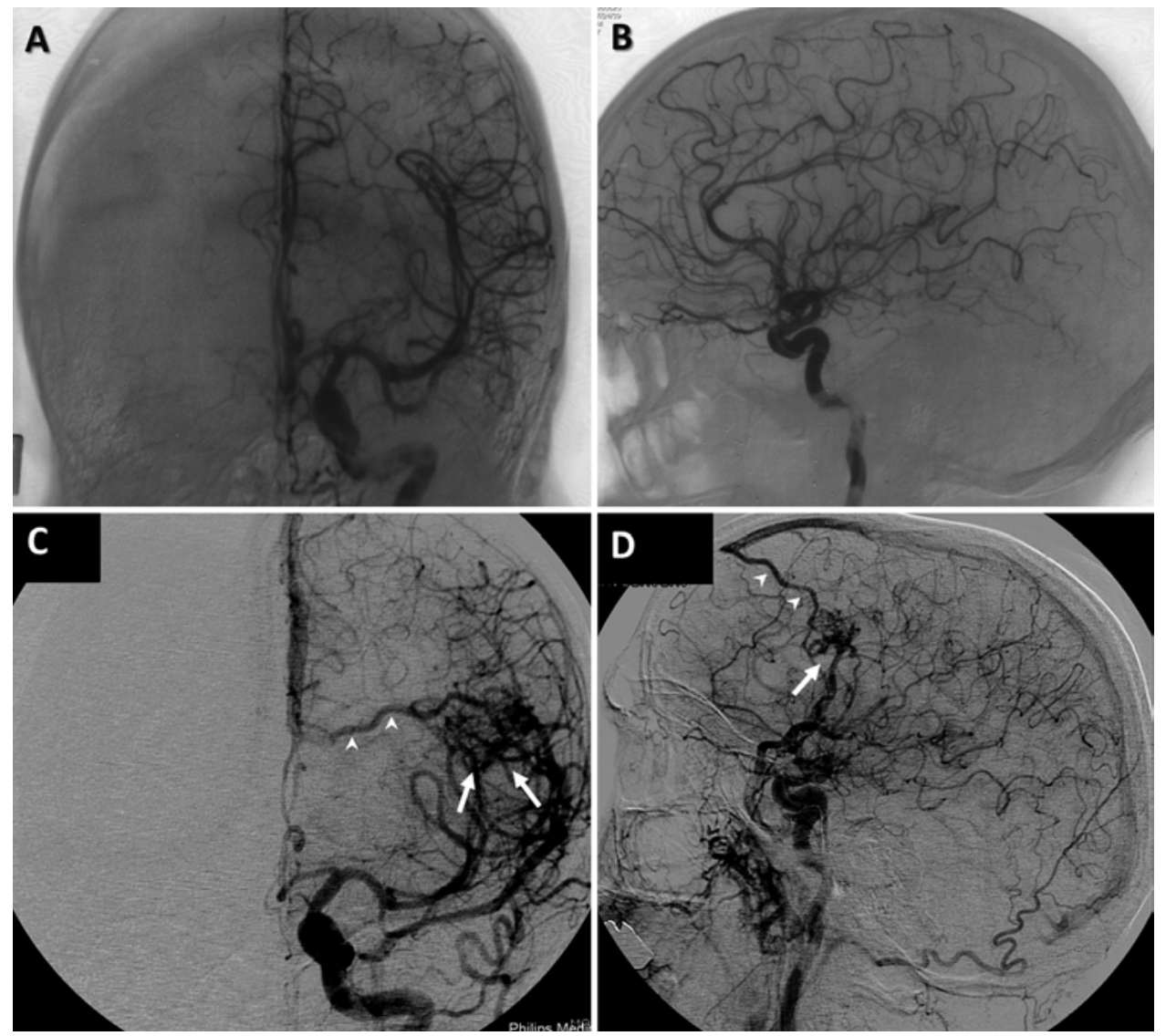

FIG. 2. Case 2. Initial and repeat catheter angiograms. Baseline angiograms after left ICA injection did not show any abnormalities (anteroposterior $[\mathrm{A}]$ and lateral $[\mathrm{B}]$ views). Repeat angiograms 14 years later showed an AVM with feeding vessels from the left MCA (arrows) with superficial venous drainage into the superior sagittal sinus (arrowheads) (anteroposterior [C] and lateral [D]).

with sporadic AVMs have identified single-nucleotide polymorphisms (SNPs) associated with a susceptibility to develop AVMs and with their progression to intracerebral hemorrhage. ${ }^{20,34}$ Most of the studied genes code for essential proteins in the angiogenic and inflammatory cascades. A recent systematic review included all the studies reporting SNPs associated with sporadic brain AVMs, and after a joint analysis of the risk estimates described in the different reports, a statistically significant association was found between an SNP in the ALK1 gene (intervening sequence $3-35 \mathrm{~A}>\mathrm{G}$ ) and a susceptibility to develop a brain AVM (OR 2.19, 95\% CI 1.25-3.83). ${ }^{34}$ A significant association was also found between SNPs in genes coding for interleukin 6 and tumor necrosis factor $-\alpha$ and risk of intracranial hemorrhage. ${ }^{34}$

Genome-wide association studies can potentially disclose novel genetic loci influencing AVM formation. ${ }^{34}$ The first of such studies in patients with sporadic brain AVMs examined the association of common and rare copy number variations (CNVs) and disease susceptibility in 371 patients with sporadic brain AVMs and 563 controls. ${ }^{6} \mathrm{~A}$ CNV was identified on initial screening but did not replicate in an independent cohort of patients. ${ }^{6}$ Similarly, no association was found between rare CNVs and disease susceptibility. ${ }^{6}$ However, larger, well-powered studies might be able to detect significant associations.
In addition to their genetic basis, the biology and microenvironment of AVMs is now better understood. ${ }^{19,20,22}$ Studies of AVM tissue have shown increased endothelial cell proliferation and increased expression of angiopoietin-2 and vascular endothelial growth factor, which promote vascular destabilization and proliferation, respectively. ${ }^{17}$ However, the exact triggering event that leads to increased and disorganized angiogenesis ultimately leading to AVM formation has not been identified. Mice with ALK1 deficiency develop de novo AVMs after angiogenic stimulation. ${ }^{8}$ This finding suggests that the presence of a genetic abnormality alone is not enough to trigger AVM formation and a "second hit" is required. ${ }^{22}$

A possible mechanism to explain AVM formation may not be dissimilar to that responsible for dural arteriovenous fistulas - that is, venous thrombosis leading to impaired venous outflow, ischemia, and increased angiogenesis. ${ }^{1}$ In the case of brain AVMs, asymptomatic parenchymal venous thrombosis could trigger local venous hypertension and ischemia. ${ }^{1}$ The ischemic stimulus triggers vascular proliferation (through increased expression of hypoxia-inducible factor-1), which in normal circumstances is self-limited..$^{12}$ However, in the presence of genetic susceptibility and abnormalities of the angiogenesis and inflammatory cascades, there may be uncontrolled vascular proliferation and arteriovenous shunt forma- 
S. F. Morales-Valero et al.

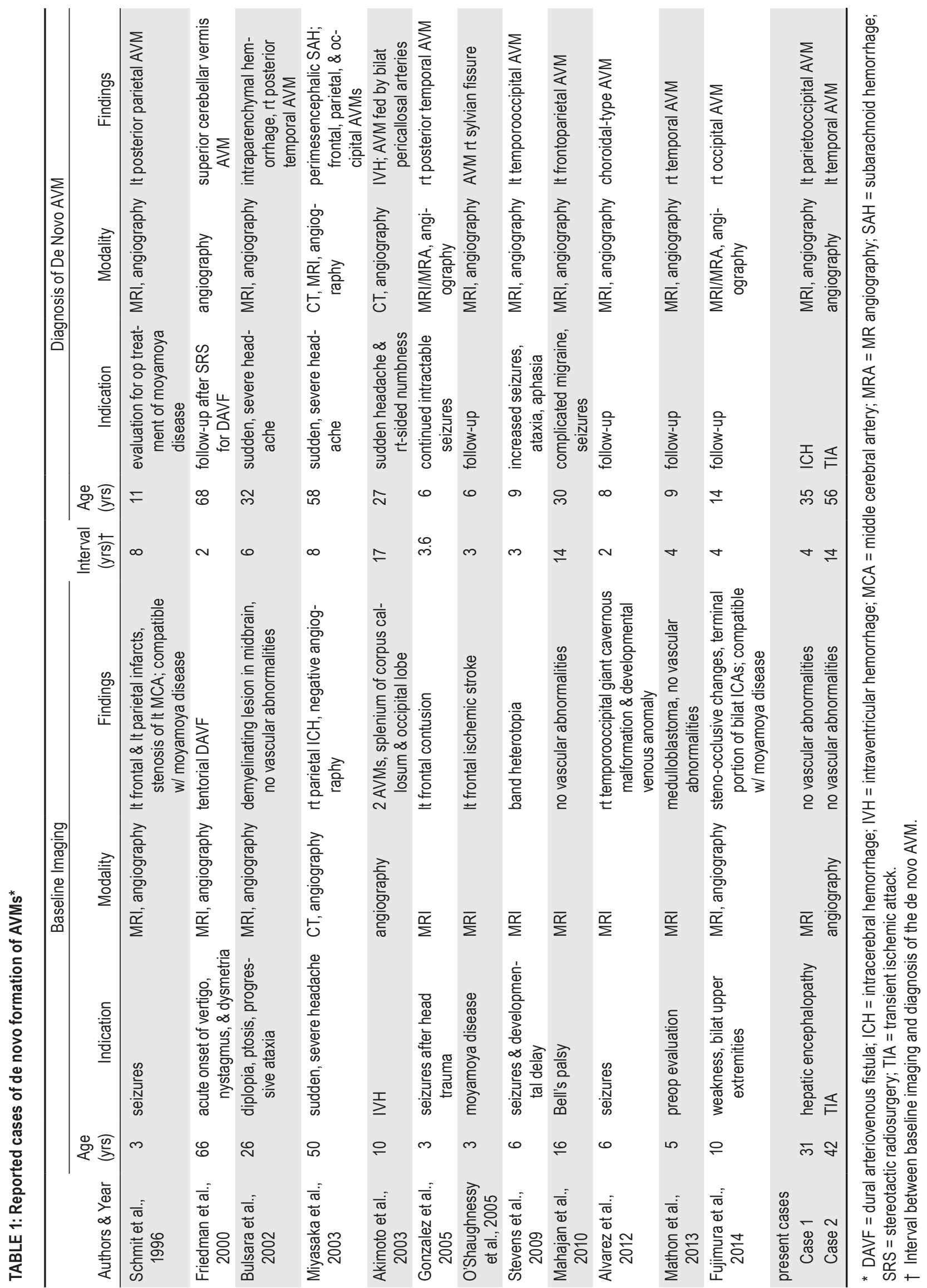


tion..$^{22}$ Once high flow is established through the vascular lesion, endothelial shear stress contributes to a continued angiogenic stimulus and a hyperangiogenic environment. ${ }^{36}$

\section{Conclusions}

Evidence of de novo formation of brain AVMs and a better understanding of their genetic and molecular basis challenge the traditional concept of their congenital nature and suggest that they most likely represent an acquired condition. The exact mechanism of AVM formation is not yet known but most likely involves an environmental trigger leading to increased angiogenesis in the setting of abnormalities of the genes involved in angiogenesis and inflammatory cascades and predisposing to disorganized vascular proliferation.

\section{Disclosure}

Dr. Lanzino reports being a consultant for ev3/Covidien, Edge Therapeutics, Inc., and Codman/Johnson \& Johnson.

Author contributions to the study and manuscript preparation include the following. Conception and design: all authors. Acquisition of data: Lanzino, Morales-Valero, Bortolotti. Analysis and interpretation of data: all authors. Drafting the article: Lanzino, Morales-Valero. Critically revising the article: all authors. Reviewed submitted version of manuscript: all authors. Study supervision: Lanzino.

\section{References}

1. Aboian MS, Daniels DJ, Rammos SK, Pozzati E, Lanzino G: The putative role of the venous system in the genesis of vascular malformations. Neurosurg Focus 27(5):E9, 2009

2. Akimoto H, Komatsu K, Kubota Y: Symptomatic de novo arteriovenous malformation appearing 17 years after the resection of two other arteriovenous malformations in childhood: case report. Neurosurgery 52:228-232, 2003

3. Al-Shahi R, Bhattacharya JJ, Currie DG, Papanastassiou V, Ritchie V, Roberts RC, et al: Prospective, population-based detection of intracranial vascular malformations in adults: the Scottish Intracranial Vascular Malformation Study (SIVMS). Stroke 34:1163-1169, 2003

4. Alvarez H, Perry V, Solle M, Castillo M: De novo cerebral arteriovenous malformation in a child with previous cavernous malformation and developmental venous anomaly. Case report. J Neurosurg Pediatr 9:327-330, 2012

5. Auyeung KM, Laughlin S, Terbrugge KG: Prenatal diagnosis of unusual fetal pial arteriovenous malformation. A case report. Interv Neuroradiol 9:163-168, 2003

6. Bendjilali N, Kim H, Weinsheimer S, Guo DE, Kwok PY, Zaroff JG, et al: A genome-wide investigation of copy number variation in patients with sporadic brain arteriovenous malformation. PLoS ONE 8: 71434, 2013

7. Bulsara KR, Alexander MJ, Villavicencio AT, Graffagnino C: De novo cerebral arteriovenous malformation: case report. Neurosurgery 50:1137-1141, 2002

8. Chen W, Sun Z, Han Z, Jun K, Camus M, Wankhede M, et al: De novo cerebrovascular malformation in the adult mouse after endothelial Alk1 deletion and angiogenic stimulation. Stroke 45:900-902, 2014

9. Davidson AS, Morgan MK: The embryologic basis for the anatomy of the cerebral vasculature related to arteriovenous malformations. J Clin Neurosci 18:464-469, 2011

10. DeCesare B, Omojola MF, Fogarty EF, Brown JC, Taylon C: Spontaneous thrombosis of congenital cerebral arteriovenous malformation complicated by subdural collection: in utero detection with disappearance in infancy. Br J Radiol 79:e140e144, 2006

11. Degani S: Evaluation of fetal cerebrovascular circulation and brain development: the role of ultrasound and Doppler. Semin Perinatol 33:259-269, 2009

12. Dore-Duffy P, LaManna JC: Physiologic angiodynamics in the brain. Antioxid Redox Signal 9:1363-1371, 2007

13. Eguchi S, Aihara Y, Yamaguchi K, Okada Y: Limitations of fetal ultrasonography and magnetic resonance imaging in prenatal diagnosis of congenital cerebral arteriovenous malformations with hemorrhagic onset. Case report. J Neurosurg Pediatr 10:154-158, 2012

14. Friedman JA, Pollock BE, Nichols DA: Development of a cerebral arteriovenous malformation documented in an adult by serial angiography. Case report. J Neurosurg 93:1058-1061, 2000

15. Fujimura M, Kimura N, Ezura M, Niizuma K, Uenohara H, Tominaga T: Development of a de novo arteriovenous malformation after bilateral revascularization surgery in a child with moyamoya disease. Case report. J Neurosurg Pediatr 13:647-649, 2014

16. Gonzalez LF, Bristol RE, Porter RW, Spetzler RF: De novo presentation of an arteriovenous malformation. Case report and review of the literature. J Neurosurg 102:726-729, 2005

17. Hashimoto T, Emala CW, Joshi S, Mesa-Tejada R, Quick CM, Feng L, et al: Abnormal pattern of Tie-2 and vascular endothelial growth factor receptor expression in human cerebral arteriovenous malformations. Neurosurgery 47:910-919, 2000

18. Kim H, Marchuk DA, Pawlikowska L, Chen Y, Su H, Yang GY, et al: Genetic considerations relevant to intracranial hemorrhage and brain arteriovenous malformations. Acta Neurochir Suppl 105:199-206, 2008

19. Kim H, Pawlikowska L, Chen Y, Su H, Yang GY, Young WL: Brain arteriovenous malformation biology relevant to hemorrhage and implication for therapeutic development. Stroke 40 (3 Suppl):S95-S97, 2009

20. Kim H, Su H, Weinsheimer S, Pawlikowska L, Young WL: Brain arteriovenous malformation pathogenesis: a responseto-injury paradigm. Acta Neurochir Suppl 111:83-92, 2011

21. Lasjaunias P: A revised concept of the congenital nature of cerebral arteriovenous malformations. Interv Neuroradiol 3: 275-281, 1997

22. Leblanc GG, Golanov E, Awad IA, Young WL: Biology of vascular malformations of the brain. Stroke 40:e694-e702, 2009

23. Mahajan A, Manchandia TC, Gould G, Bulsara KR: De novo arteriovenous malformations: case report and review of the literature. Neurosurg Rev 33:115-119, 2010

24. Mathon B, Blauwblomme T, Bolle S, Dufour C, Nagarra O, Brunelle F, et al: De novo arteriovenous malformation after brain radiotherapy for medulloblastoma in a child. Neurology 81:398-399, 2013

25. Miyasaka Y, Nakahara K, Takagi H, Hagiwara H: Development of multiple cerebral arteriovenous malformations documented in an adult by serial angiography. Case report. J Neurosurg 98:190-193, 2003

26. Mortazavi MM, Griessenauer CJ, Foreman P, Bavarsad Shahripour R, Shoja MM, Rozzelle CJ, et al: Vein of Galen aneurysmal malformations: critical analysis of the literature with proposal of a new classification system. A review. J Neurosurg Pediatr 12:293-306, 2013

27. Mullan S, Mojtahedi S, Johnson DL, Macdonald RL: Embryological basis of some aspects of cerebral vascular fistulas and malformations. J Neurosurg 85:1-8, 1996

28. O'Shaughnessy BA, DiPatri AJ Jr, Parkinson RJ, Batjer HH: Development of a de novo cerebral arteriovenous malformation in a child with sickle cell disease and moyamoya arteriopathy. Case report. J Neurosurg 102 (2 Suppl):238-243, 2005 


\section{S. F. Morales-Valero et al.}

29. Pooh RK: Imaging diagnosis of congenital brain anomalies and injuries. Semin Fetal Neonatal Med 17:360-376, 2012

30. Potter CA, Armstrong-Wells J, Fullerton HJ, Young WL, Higashida RT, Dowd CF, et al: Neonatal giant pial arteriovenous malformation: genesis or rapid enlargement in the third trimester. J Neurointerv Surg 1:151-153, 2009

31. Schmit BP, Burrows PE, Kuban K, Goumnerova L, Scott RM: Acquired cerebral arteriovenous malformation in a child with moyamoya disease. Case report. J Neurosurg 84:677-680, 1996

32. Stapf C, Mast H, Sciacca RR, Berenstein A, Nelson PK, Gobin YP, et al: The New York Islands AVM Study: design, study progress, and initial results. Stroke 34:e29-e33, 2003

33. Stevens J, Leach JL, Abruzzo T, Jones BV: De novo cerebral arteriovenous malformation: case report and literature review. AJNR Am J Neuroradiol 30:111-112, 2009

34. Sturiale CL, Puca A, Sebastiani P, Gatto I, Albanese A, Di Rocco C, et al: Single nucleotide polymorphisms associated with sporadic brain arteriovenous malformations: where do we stand? Brain 136:665-681, 2013
35. van Beijnum J, van der Worp HB, Schippers HM, van Nieuwenhuizen O, Kappelle LJ, Rinkel GJ, et al: Familial occurrence of brain arteriovenous malformations: a systematic review. J Neurol Neurosurg Psychiatry 78:1213-1217, 2007

36. Wragg JW, Durant S, McGettrick HM, Sample KM, Egginton S, Bicknell R: Shear stress regulated gene expression and angiogenesis in vascular endothelium. Microcirculation 21:290-300, 2014

Manuscript submitted May 15, 2014.

Accepted June 11, 2014.

Please include this information when citing this paper: DOI: 10.3171/2014.6.FOCUS14234.

Address correspondence to: Giuseppe Lanzino, M.D., Department of Neurologic Surgery, Mayo Clinic, 200 SW First St., Rochester, MN 55905. email: lanzino.giuseppe@mayo.edu. 